\title{
CONFLITO COGNITIVO NA DECISÃO ESTRATÉGICA DE EQUIPES DE DIREÇÃO EM PEQUENAS EMPRESAS
}

Tatiane Silva Tavares ${ }^{1}$

Edmilson Lima ${ }^{2}$

\footnotetext{
${ }^{1}$ Universidade Federal de Mato Grosso do Sul e UNINOVE

${ }^{2}$ Programa de Pós-Graudação em Administração / Universidade Nove de Julho
} 


\title{
CONFLITO COGNITIVO NA DECISÃO ESTRATÉGICA DE EQUIPES DE DIREÇÃO EM PEQUENAS EMPRESAS
}

\begin{abstract}
Resumo: O estudo aqui apresentado investigou como e porque ocorrem conflitos cognitivos em processos decisão estratégica de equipes de direção em pequenas empresas (PE). Tais conflitos foram estudados em quatro PE. Adotou-se a abordagem metodológica descritiva, baseada em métodos qualitativos e no estudo multicaso (Eisenhardt, 1989). Os dados foram coletados com entrevistas em profundidade e analisados de modo intra e intercaso, conforme as recomendações de Miles e Huberman (1994). Os resultados evidenciaram que os processos de decisão estratégica foram em grande parte determinados pelos conflitos cognitivos. Estes ocasionaram o questionamento de possibilidades de decisão, direcionaram elementos como a intuição e a improvisação, normalmente úteis e presentes nos processos de decisão estratégica das PE. O conflito cognitivo mostrou-se como um inibidor da improvisação, pois sua ocorrência favorece questionamentos úteis na preparação para a tomada de decisões. Os conflitos cognitivos contribuíram promovendo maior profundidade de discussão e de análise nos processos decisórios das equipes de direção.
\end{abstract}

Palavras-chave: conflito cognitivo; decisão estratégica; equipe de direção; pequena empresa.

\section{Introdução}

As pequenas empresas (PE) comumente enfrentam dificuldades associadas ao ambiente de atuação e a restrições de recursos próprias de sua realidade, como as de recursos financeiros e de conhecimento de gestão (Fuller-Love, 2006; Greene, Brush \& Brown, 2015; Ibrahim, 2015). Considerando tais dificuldades, uma das iniciativas de superação notada nessas organizações reside na formação de equipes de direção, responsáveis pelas principais decisões em seu papel de direção. Na mobilização de esforços coordenados, essas equipes exploram aspectos como complementaridade e colaboração no processo de tomada de decisão e em suas ações (Carmeli, 2008; Tihula \& Huovinen, 2009).

A equipe de direção de PE é entendida aqui como a equipe formada por coproprietários-dirigentes atuantes nos processos de decisão estratégica (Hambrick, 1995; Lima, 2010), atores aqui resumidamente denominados codirigentes. Coletivamente, eles são dotados de distintas habilidades que permitem uma maior cobertura de diferentes áreas de atividades da empresa em comparação ao que poderia fazer um só dirigente, havendo assim tendência à gestão mais cooperativa e complementar, em termos de habilidades e soma de variados recursos (Greene, Brush \& Brown, 2015; Lohrke, Franklin \& Kothari, 2015).

Embora haja o reconhecimento de que a equipe de direção desempenha um papel significativo nas organizações dirigidas por uma (Hambrick \& Mason, 1984), no caso da PE, ela tem influência especial, já que a complementaridade de habilidades e de recursos de seus codirigentes, assim como a rede de relação deles, dá mais condições do que se vê na direção de uma só pessoa para se superar a já mencionada alta restrição de recursos e contribui para melhorar os processos de decisão estratégica (Liu \& Maitlis, 2014; Alcantar \& Ngwenyama, 2015).

Tal tipo de decisão foi estudado por Liberman-Yaconi, Hooper e Hutchings (2010) na realidade de microempresas. Contudo, sua revisão de literatura destaca também elementos relevantes para as PE. O processo de decisão estratégica na PE é caracterizado por esses autores como intuitivo e fortemente apoiado em mecanismos não racionais, os quais envolvem conflitos de ideias. Além disso, concentra-se em poucos indivíduos, é mais centralizada, menos complexa e menos coordenada do que se vê em organizações maiores (Liberman-Yaconi et al, 2010). Portanto, modelos racionais de tomada de decisão têm pouca aderência à realidade das PE (Brouthers, Andriessen \& Nicolaes, 1998; Liberman-Yaconi et al., 2010; Ates, Garengo, Cocca \& Bititci, 2013; Greene, Brush \& Brown, 2015).

Um dos processos-chave da decisão estratégica em equipes de direção é o conflito cognitivo. Este refere-se à divergência de ideias ocorrida na interação entre dois ou mais indivíduos (Amason, 2007; De Wit, Greer, \& Jehn, 2012). Na tomada de decisão em empresas, ele diz respeito ao rumo a dar aos negócios e normalmente impõe a necessidade de se acomodar, ou mesmo conciliar, distintos pontos de 
vista (Jehn, 2008; Loughry \& Amason, 2014). Nas equipes de direção, esse tipo de conflito é comumente considerado benéfico por levar os codirigentes a considerar diferentes contribuições, perspectivas e possibilidades de solução na tomada de decisões (Weingart et al, 2015; Parayitam et al., 2016; Hjerto et al., 2017). Dado o considerável potencial benéfico do conflito cognitivo na tomada de decisão, faz-se promissor e atraente investigá-lo com vistas a esclarecer sua ocorrência e consequências, particularmente na decisão estratégica de PE (Behfar, Mannix, Peterson \& Trochim, 2010; Todorova, Bear \& Weingart, 2014; Tjosvold, Wong \& Feng Chen, 2014; Weingart et al, 2015).

Convergindo com as considerações acima, destaca-se na literatura a recomendação de se dar ênfase aos processos coletivos, sobretudo de equipes de direção e não mais focando em traços demográficos (perfil, composição, etc. das equipes), para fazer avançar a pesquisa sobre decisões estratégicas nas organizações, inclusive nas PE (Olson, Parayitam, \& Bao, 2007; Liu \& Maitlis, 2014; Tsai \& Bendersky, 2015). Pesando tais considerações, o objetivo do presente artigo é explicar como e porque ocorre o conflito cognitivo na decisão estratégica de equipes de direção em PE.

$\mathrm{O}$ artigo está estruturado da seguinte forma: primeiramente, traz o referencial teórico quanto às equipes de direção na PE, ao conflito cognitivo e aos processos de tomada de decisão estratégica em PE; em seguida apresenta os métodos do estudo. Duas outras partes complementam o trabalho, contendo a análise dos processos de decisão estratégica identificados nas PE estudadas e do conflito cognitivo associado a tais processos. Uma seção de considerações finais encerra o trabalho.

\section{Equipe de direção, PE e conflitos cognitivos nos processos de decisão estratégica 2.1 PEs e equipes de direção}

A equipe de direção caracteriza-se basicamente pela presença de mais de um dirigente na direção Em estudos sobre tais equipes, não se considera o dirigente individual, pelo contrário, o foco não está num só dirigente administrando todo um negócio. Nas PE, o tamanho dessas empresas é fator que explica a necessidade de equipe de direção (Tihula \& Huovinen, 2009). A ideia de direção em equipe, na PE, implica também a noção de coesão, entendida como a união e adesão voluntária de codirigentes à equipe, compartilhando valores, ideias e alguma aspiração comum (Pech-Varguez et al., 2010). Em contraste, nas grandes empresas, os codirigentes tendem a ficar dispersos, principalmente se a empresa opera com numerosos postos de direção, havendo menor interação entre eles, na comparação com as PE.

Devido ao número de codirigentes e à variedade que tendem a ter de perspectivas e competências, as equipes de direção tendem a apresentar maior cobertura de diferentes áreas de atividades da empresa em comparação com a direção de uma única pessoa. A complementaridade de habilidades e a colaboração, duas características particularmente interessantes nas equipes (Tihula \& Huovinen, 2009), podem facilitar o processo de tomada de decisão estratégica, especialmente se houver respeito das áreas de especialidade e de atividades dos codirigentes. Equipes de direção compostas de indivíduos que representam muita similaridade de competências e de funções podem não ter as habilidades necessárias para administrar um o empreendimento quando ele evolui (Boeker \& Wiltbank, 2005). Portanto, recomenda-se cautela ao se instituir equipes homogêneas, uma vez que tendem a ter menor capacidade de questionamento e de reflexão conjunta para a tomada de decisão, comprometendo o desempenho da empresa (Marimuthu \& Kolandaisamy, 2009).

Pode-se perceber que diferentes fatores relacionados à composição da equipe têm impacto direto no modelo de gestão que adotam, tais como: a heterogeneidade funcional, diversidade cognitiva, idade, experiência da equipe no setor (Escribá-Esteve et al., 2009). As características dos codirigentes de equipes de direção têm efeito particularmente forte na orientação da tomada de decisão estratégica em PE.

O trabalho em equipe de direção é valioso por possibilitar aos dirigentes desenvolverem um processo participativo, com o qual os membros da equipe interagem e lidam com questões difíceis, tomam decisões estratégicas importantes e constroem compromisso (Carmeli; Tishler; Edmondson, 2012; Colbert; Barrick; Bradley, 2014). Naturalmente, a ocorrência de conflitos de ideias e a expressão de pontos de vista diferentes marcam seus processos de decisão. Além disso, tais decisões são tomadas em nível estratégico, remetendo importância maior e, portanto, mais debates e embates até a definição da melhor decisão a ser tomada. 


\section{$2.2 O$ conflito cognitivo}

O conflito é inerente à vida organizacional, e pode ser considerado uma força centrípeta poderosa, que as equipes de direção precisam enfrentar (Mooney, Holahan, \& Amason, 2007; Weingart et al, 2015; Tsai \& Bendersky, 2015). Nelas, o conflito pode surgir por motivos relacionados a recursos escassos, tempo, responsabilidades, valores, os quais envolvem preferências políticas, ideias, fatos, convicções, moralidade e a própria forma de entender o mundo (De Dreu, 2008; González-Romá; Hernández, 2014). Quando referente a questões decisórias, o conflito, além de natural, é até mesmo necessário. Por meio dele, surgem questionamentos e reflexões que podem apontar novas direções estratégicas. Sendo assim, a alternativa ao conflito geralmente não significa acordo ou harmonia, mas indícios de apatia do grupo e desengajamento (Eisenhardt et al., 1997; O’neill; Allen \& Hastings, 2013).

Sobre decisão estratégica, Eisenhardt e Zbaracki (1992) propõem o uso de uma visão bem realista, a qual inclui a consideração de novas concepções sobre a cognição e o conflito. Alguns pesquisadores, reconhecendo a proposta dos autores, defendem o conflito como uma importante dimensão, a qual está envolvida diretamente no sucesso de processos de decisão em equipes (Mooney et al., 2007; Olson et al., 2007; BRADLEY, et al., 2013; Loughry; Amason, 2014; Tsai; Bendersky, 2015; Diánez-González; Camelo-Ordaz, 2016).

O conflito do tipo cognitivo ocorre quando diferentes membros de uma equipe discutem preferências, visões e opiniões sobre suas relacionadas a suas funções e, a partir disso conseguem sintetizar distintos pontos de vista (Amason et al., 1995; Jehn et al., 2008). Geralmente essa modalidade de conflito melhora o processo de decisão estratégica e a qualidade dele, além de incentivar sua compreensão e aceitação, uma vez que há debate coletivo e a necessidade de certo nível de consenso (Jehn et al. 2008; Loughry; Amazon, 2014). Por outro lado, o conflito afetivo envolve divergências sobre questões de natureza pessoal e emocional (Mooney et al., 2007; Bradley et al., 2013) como, por exemplo, as lutas por poder ou incompatibilidades pessoais (Todorova; Bear; Weingart, 2014).

Associado ao processo de decisão estratégica em equipes de direção, o conflito cognitivo tem sido o alvo de muitos estudos (Eisenhardt et al., 1997; Olson et al., 2007; Jehn et al., 2008; Clerkin \& Jones, 2013). Um denominador comum entre os distintos trabalhos sobre essa temática é que uma medida de conflito é inerente aos processos de decisão estratégica (De Wit, Greer, \& Jehn, 2012; Clerkin \& Jones, 2013). Há benefícios desse tipo de conflito nesses processos, fruto de discordâncias construtivas oriundas de diversas perspectivas dos diferentes codirigentes, os quais, confiantes em suas habilidades, questionam pontos de vista dos outros, incentivam a troca de informações, o debate de ideias e as discussões sobre várias perspectivas essenciais e não rotineiras nas decisões complexas (Mello; Delise, 2015; DiánezGonzález; Camelo-Ordaz, 2016).

Compartilhando dessa visão, Eisenhardt et al. (1997) defendem a associação de tal conflito a discordâncias benéficas à elaboração de decisões eficazes, na medida em que fornecem aos codirigentes uma gama maior de informações e uma compreensão mais profunda e abrangente das questões estratégicas. Para esses autores, onde há pouco conflito cognitivo, também é provável haver tomadas de decisões de qualidade inferior.

De modo geral, o desenvolvimento do processo de decisão estratégica é favorecido pelo conflito cognitivo, na medida em que esse processo ele: facilita a consideração de diferentes alternativas, a comunicação franca e aberta; incentiva o pensamento inovador e; promove soluções criativas para problemas que de outra forma poderiam parecer intransponíveis (Amason et al., 1995; Tjosvold; Wong; Feng Chen, 2014).

O estabelecimento de relações de confiança nas equipes, a abertura ao diálogo (Amason \& Sapienza, 1997; Mooney et al., 2007), bem como a comunicação informal entre os codirigentes podem contribuir, minimizando as divergências pessoais e incentivando o conflito cognitivo de qualidade (Olson et al., 2007; Clerkin \& Jones, 2013). A confiança facilita as discussões ao permitir que os codirigentes desafiem abertamente as perspectivas uns dos outros, sem medo de retribuições, já as conversas informais permitem discutir antecipadamente agendas de reunião, podendo influenciar o processo decisório. Enquanto a abertura promove a tolerância à expressão franca de pontos de vista distintos. 


\subsection{Processo de decisão estratégica na PE}

Há muitas semelhanças e também diferenças entre uma grande empresa e uma PE, inclusive, na gestão estratégica. Em particular, ainda que apresentem menos níveis hierárquicos em sua estrutura, os proprietários-dirigentes estão mais propensos a desempenhar ao menos dois papéis na PE, cuidando tanto da função estratégica como das funções operacionais básicas (Lubatkin et al., 2006; Ates et al, 2013; Ibrahim, 2015).

Nas PE, a tomada de decisão estratégica é relativamente pouco elaborada quanto a usos de técnicas administrativas e de métodos analíticos. Isso faz com que a compreensão das coisas, a capacidade de julgamento, a intuição e as aspirações pessoais dos dirigentes, sejam centrais no processo decisório (Lima, 2010; Ibrahim, 2015). Diante das particularidades da PE, evidencia-se a necessidade de se buscar novas formas de compreender seu processo de decisão estratégica. Nota-se que, para tanto, a pesquisa em estratégia desse segmento de empresa necessita de estudos descritivos que caracterizem o seu processo de gestão (Mccarthy; Leavy, 2000; Lima, 2008;). No campo de estudo normativo, o conceito de estratégia encontra-se enraizado nas noções tradicionais, relacionadas ao planejamento formal e procedimentos racionais e analíticos (Mccarthy \& Leavy, 2000).

Os processos de decisão estratégica, concebidos como um processo periódico e formal, não é suficiente para lidar com a realidade de gestão da PE. Tais processos podem assumir muitas formas, como alertam Verreynne, Meyer e Liesch (2015). Na PE, os autores os consideraram mais informais, diante dos resultados de suas pesquisas empíricas com 320 organizações desse tipo. As PE não requerem alto nível de formalização, devido à habilidade do proprietário-dirigente em controlar e rapidamente comunicar as informações via mecanismos informais (Mazzarol; Reboud, 2009). Isso ocorre em boa parte devido à forte dependência das PE quanto à intuição e a mecanismos não racionais, os quais envolvem conflitos de ideias e os objetivos dos dirigentes (Liberman-Yaconi et al., 2010). Esses autores defendem ainda que o processo de decisão estratégica relaciona-se mais a procedimentos caóticos e interativos e menos à formalização, sistematização e linearidade.

\section{Métodos}

Essa pesquisa se caracteriza como um estudo de múltiplos casos de natureza qualitativa e envolve uma abordagem descritiva. Optou-se pelo estudo multicasos devido ao maior potencial explicativo por permitir análise comparativa dos dados entre casos (Eisenhardt; Graebner, 2007), não se restringindo às peculiaridades do processo de decisão estratégica de uma única equipe de direção.

Diante do caráter exploratório da pesquisa, envolvendo tema de estudo não amadurecido, adotou-se uma perspectiva metodológica de natureza indutivo-dedutivista, combinando aspectos propostos por Eisenhardt (1989) com alguns elementos propostos por Yin (2010). Eisenhardt (1989) propõe a utilização de métodos orientados para a construção de um quadro teórico descritivo/explicativo do fenômeno estudado, por meio do estudo de casos múltiplos a partir das noções de base da teoria embasada (Glaser; Strauss, 1967).

O objeto de estudo desta pesquisa foi o processo de decisão estratégica realizado pelos codirigentes de PE. A delimitação do número de casos foi orientada pela pesquisa de campo e pela teoria, levando-se em consideração que o principal interesse do estudo de múltiplos casos é conceitual (Miles; Hubermam, 1994). A definição das empresas, utilizando-se amostragem teórica (Strauss; Corbin, 2008), foi realizada em termos práticos, em dois eventos de amostragem: um caso inicial foi selecionado e, com base na análise dos dados referentes a ele, outros três casos foram incluídos (Pandit, 1996).

Os novos casos foram selecionados com as seguintes perspectivas: verificar os resultados para os casos anteriores; ampliar o escopo de resultados do estudo; cumprir categorias conceituais específicas surgidas no decorrer da investigação e; adicionar à amostra casos que proporcionam exemplos de tipos extremos (EISENHARDT, 1989). O número de quatro casos da amostra foi definido em função da confiança empírica de que não mais se encontravam dados adicionais os quais poderiam contribuir para o desenvolvimento de propriedades da categoria (GODOI; MATTOS, 2006).

Foram seguidos critérios mínimos estabelecidos para a escolha dos casos, apresentados a seguir: a) 
Ser uma PE, de acordo com ocritérios do IBGE/SEBRAE, nos quais PE corresponde: até 49 empregados no setor de serviços (Serviço Brasileiro de Apoio às Micro e Pequenas Empresas, SEBRAE, 2011); b) Ser uma empresa dirigida por uma equipe de direção, formada por dois ou mais proprietários dirigentes; c) Ter no mínimo três anos de existência. Esse critério possibilitou a exploração de uma lacuna na literatura, representada pela ausência de estudos sobre as equipes que passaram da fase inicial de fundação.

Optou-se por estudar PEs de base tecnológica, com incorporação de elevado conhecimento aplicado à tecnologia, atuantes em ambientes dinâmicos e com ruptura tecnológica, como é o caso dos setores de software (TI) e farmacêutico (biotecnologia). O quadro 1 caracteriza as PEs de base tecnológica selecionadas para o estudo, cujo os nomes estão designados por uma letra do alfabeto grego. Observe-se que as PEs localizam-se no estado de São Paulo, o qual se destaca pela concentração de empresas de base tecnológica.

Quadro 1: Caracterização das PE estudadas

\begin{tabular}{|c|c|c|c|c|c|c|}
\hline Equipe & Idade & Sócio & Fundação & Local & Serviços & Funcionário \\
\hline \begin{tabular}{l}
\multicolumn{1}{c}{ Alpha } \\
Pai \\
Filho \\
Ex-funcionário
\end{tabular} & $\begin{array}{l}48 \text { anos } \\
23 \text { anos } \\
30 \text { anos }\end{array}$ & $\begin{array}{l}60 \% \\
20 \% \\
20 \%\end{array}$ & $\begin{array}{c}1992 \\
\text { (23 anos) }\end{array}$ & $\begin{array}{c}\text { São José } \\
\text { do Rio } \\
\text { Preto (SP) }\end{array}$ & $\begin{array}{l}\text { Desenvolvimento } \\
\text { de sistema de } \\
\text { informação }\end{array}$ & 9 \\
\hline $\begin{array}{l}\text { Beta } \\
\text { Pai } \\
\text { Filha }\end{array}$ & $\begin{array}{l}55 \text { anos } \\
32 \text { anos }\end{array}$ & $\begin{array}{l}75 \% \\
25 \%\end{array}$ & $\begin{array}{c}2005 \\
(9 \text { anos })\end{array}$ & $\begin{array}{l}\text { Ribeirão } \\
\text { Preto (SP) }\end{array}$ & $\begin{array}{c}\text { Desenvolvimento } \\
\text { de vacinas, testes } \\
\text { laboratoriais }\end{array}$ & 10 \\
\hline $\begin{array}{c}\text { Gama } \\
\text { Codirigente 1 } \\
\text { Codirigente } 2 \\
\text { Codirigente } 3 \\
\end{array}$ & $\begin{array}{c}55 \text { anos } \\
54 \text { anos } \\
\text { Aposentou } \\
\end{array}$ & $\begin{array}{l}33 \% \\
33 \% \\
33 \% \\
\end{array}$ & $\begin{array}{c}1986 \\
(29 \text { anos })\end{array}$ & $\begin{array}{c}\text { São José } \\
\text { do Rio } \\
\text { Preto (SP) }\end{array}$ & $\begin{array}{l}\text { Desenvolvimento } \\
\text { de sistema de } \\
\text { informação }\end{array}$ & 48 \\
\hline $\begin{array}{c}\text { Delta } \\
\text { Codirigente 1 } \\
\text { Codirigente } 2 \\
\text { Codirigente } 3\end{array}$ & $\begin{array}{l}35 \text { anos } \\
33 \text { anos } \\
26 \text { anos }\end{array}$ & $\begin{array}{l}40 \% \\
40 \% \\
20 \%\end{array}$ & $\begin{array}{c}2010 \\
\text { (5 anos) }\end{array}$ & $\begin{array}{l}\text { São Paulo } \\
\text { (SP) }\end{array}$ & $\begin{array}{l}\text { Consultorias para } \\
\text { desenvolvimento de } \\
\text { sistemas }\end{array}$ & 23 \\
\hline
\end{tabular}

Fonte: nossa pesquisa.

Os dados foram coletados por meio de entrevistas em profundidade e por meio de análise documental. Para melhor condução das entrevistas foi utilizado um roteiro semiestruturado. As entrevistas gravadas foram realizadas pessoalmente, na sede de cada PE e, tiveram duração média de duas horas. Foram entrevistados dez codirigentes que fazem parte da equipe de direção e quatro funcionários (envolvidos em processos de decisão estratégica identificados). A suplementação de dados por meio de análise documental ocorreu a partir de informações da website disponibilizadas, panfletos institucionais, diretrizes e manuais de funcionamento de sistemas. Tais documentos serviram como complemento aos relatos dos casos.

A análise dos dados se dividiu em duas etapas, compondo assim análises intra e intercaso, respectivamente (MILES; HUBERMAN, 1994). A primeira etapa envolveu a identificação de aspectos peculiares nos casos casos estudados e objetivou destacar conteúdos conceituais que se mostraram mais importantes para descrevê-los e explicá-los, de maneira individual. Esta análise foi operacionalizada atribuindo códigos às unidades de significação, considerando separadamente cada caso da amostra. Em seguida, na análise intercaso, buscou-se as regularidades num processo analítico de comparação entre os casos, a partir de descrições resultantes da análise intracaso.

O processo de análise da grande quantidade de dados obtidos foi facilitado com o uso do software de pesquisa qualitativa ATLAS/ Ti. Por meio da utilização de dados de texto lineares como ponto de partida, entrevistas transcritas e documentos pertinentes, iniciou-se o processo de segmentação e de codificação.

\section{Processos de decisão estratégica e os conflitos cognitivos}

Um panorama geral de cada processo de decisão estratégica é apresentado por meio do quadro 2, o 
qual foi criado a partir dos dados empíricos e considerando-se a cronologia dos principais processos conduzidos pelos codirigentes nos últimos cinco anos. Neles, foi possível identificar, via análise de interações dos codirigentes, alguns fatores de destaque do conflito cognitivo. No quadro 2 encontram-se os mais expressivos.

Quadro 2: Processos de decisão estratégica (PDE) e conflitos cognitivos

\begin{tabular}{|c|c|c|}
\hline PEs & PDE identificados & Fatores de destaque \\
\hline Alfa & $\begin{array}{l}\text { Formação da equipe de direção } \\
\text { Profissionalização dos serviços }(2011) \text {; Reformulação } \\
\text { da precificação } \\
\text { (2014). }\end{array}$ & $\begin{array}{l}\text { Análise de possibilidades; discordâncias; } \\
\text { complementaridade na equipe; debate de } \\
\text { ideias; abertura ao diálogo; canalização de } \\
\text { conflitos cognitivos }\end{array}$ \\
\hline Beta & $\begin{array}{l}\text { Contratação de Consultoria Internacional (2009); } \\
\text { Estabelecimento de Parceria (2011); Controle de } \\
\text { qualidade e especificações (2012); Sociedade com os } \\
\text { parceiros (2014). }\end{array}$ & $\begin{array}{l}\text { Resolução de divergências; discordâncias; } \\
\text { complementaridade na equipe; debate de } \\
\text { ideias; abertura ao diálogo; confiança }\end{array}$ \\
\hline Gama & $\begin{array}{l}\text { Inserção de práticas de gestão de Recursos Humanos } \\
\text { (RH) (2009); Aperfeiçoamento do software para } \\
\text { CEASA (2010) Departamentalização de setores } \\
\text { (2012); Nova identidade visual (2013); Contratação de } \\
\text { consultoria especializada (2014). }\end{array}$ & $\begin{array}{l}\text { Discussão de obstáculos; resolução de } \\
\text { divergências; debate de ideias; } \\
\text { discordâncias; complementaridade na } \\
\text { equipe; abertura ao diálogo }\end{array}$ \\
\hline Delta & $\begin{array}{l}\text { Criação do produto Delta (2010); De produto para } \\
\text { consultorias (2011) Exploração de diferencial no design } \\
\text { de softwares (2012); Entrada e saída de sócio na equipe } \\
\text { de direção (2012-2014). }\end{array}$ & $\begin{array}{l}\text { Confiança; discordâncias; } \\
\text { complementaridade na equipe; debate de } \\
\text { ideias; abertura ao diálogo }\end{array}$ \\
\hline
\end{tabular}

Fonte: nossa pesquisa

A terceira coluna do quadro 2 traz uma síntese daquelas categorias mais frequentes nos processos de decisão estratégica identificados nos quatro casos. Faz-se importante esclarecer que tais fatores de destaque correspondem às categorias da pesquisa e são códigos importantes na análise dos dados com o uso do software Atlas-Ti, estão relacionados com trechos de entrevistas. A escolha dessas categorias se deu a partir do referencial teórico previamente construído.

Os conflitos cognitivos se manifestaram nos processos de decisão estratégica e desencadearam mudanças de pensamento estratégico dos codirigentes. Na sequência, cada decisão estratégica é retomada para que sejam explicados os fatores de destaque a respeito de conflitos cognitivos que nela aparecem.

\subsection{Alpha}

O processo de decisão estratégica de formar uma equipe de direção foi essencialmente conduzido pelo fundador da Alpha. Com a formação da equipe, foi possível direcionar o posicionamento estratégico que o fundador idealizava para a empresa, por meio da especialização em serviços de sistema de informação. Por isso a empresa foi dividida em três setores: administração financeira, suporte aos clientes e programação. Esse último setor passou a ser responsabilidade do ex-funcionário, novo sócio que se graduou e se especializou em Análises de Sistemas.

Um trecho da entrevista com o codirigente ex-funcionário relata as mudanças: “...com a sociedade formada melhorou bastante a organização, a direção, cada um pegou uma coisa pra fazer, ficou bem mais controlado, antes o fundador fazia tudo não dava pra ele se focar..." $\mathrm{O}$ fundador deixou de atuar na programação de sistemas e passou a dedicar-se à administração financeira e a alimentar a rede de relações com os clientes.

Evidenciou-se que, a partir do processo de decisão estratégica de formar essa nova equipe de direção, a canalização de conflitos cognitivos tornou-se um fator de destaque, presente em praticamente todos os processos de decisão identificados. Pode-se dizer que, a busca por canalizar os conflitos e aproveitá-los positivamente na condução das decisões conjuntas, gerou a formação da nova equipe de direção.

$\mathrm{Na}$ equipe de direção formada, pode-se verificar que os dois novos codirigentes se aliaram e começaram a questionar sobre os rumos estratégicos necessários para impulsionar o desenvolvimento da 
empresa. Esses questionamentos foram muito apoiados por conversas estratégicas entre os codirigentes, e por meio delas foi conduzido o processo de decisão estratégica de profissionalizar a prestação de serviços.

Por isso, pode-se afirmar que os debates de ideias, ocorridos com mais energia, especialmente a partir da formação da equipe de direção, ajudaram muito a desencadear a profissionalização dos serviços. Pode-se constatar que se intensificaram a partir dos processos de decisão estratégica subsequentes, visto que a própria formação da equipe criou um ambiente favorável, de modo geral, ao surgimento dos conflitos cognitivos.

Nos relatos dos entrevistados, mostraram-se centrais as diferenças de pontos de vista sobre a reformulação da precificação de produtos, com impasse na decisão estratégica. $O$ fundador temia prejudicar as relações com os clientes antigos, seu filho preocupava-se com os orçamentos, enquanto um codirigente ex-funcionário buscava a valorização dos serviços de programação. Este não abria mão avançar com a reformulação, aproveitando bem as horas de trabalho de programadores, como já faziam os concorrentes.

A solução do impasse originou-se da persistente análise de possibilidades, fator de destaque do conflito cognitivo. Depois de se engajarem nessa análise durante um longo período, os codirigentes decidiram, por fim, reformular a precificação das alterações nos sistemas, apenas dos clientes mais novos. Aqueles antigos continuariam sendo atendidos em suas solicitações. Isso, a partir de uma análise cuidadosa do codirigente ex-funcionário, a respeito das alterações solicitadas.

Pode-se afirmar que, especialmente nesse processo de decisão estratégica, a abertura para resolver divergências de opiniões revelou-se um elemento fundamental e contribuiu para canalizar os conflitos cognitivos e também enriquecer a análise de possibilidades. Nesse processo foram evidenciadas as mais expressivas manifestações de discordâncias de ideias entre os codirigentes.

No processo de decisão estratégica concernente à sede nova num parque tecnológico, ficou perceptível a grande influência da complementaridade, expressa por meio da confiança, diante da experiência do fundador como empresário. Na concepção dele, a complementaridade funciona da seguinte forma: "Pra funcionar cada um tem que cuidar de uma área, isso é muito importante, por exemplo, eu não entro na área do meu filho e ele não entra na minha, eu não entro na área do programador e vice e versa ...". Ele apresentou a ideia da mudança de sede e ficou encarregado de buscar informações para conduzir esse processo de decisão.

\subsection{Beta}

As dificuldades em cumprir regulamentações do setor farmacêutico dentro da incubadora na qual foram iniciadas as atividades da Beta originaram a contratação de consultoria internacional, primeiro processo de decisão estratégica identificado nessa PE.

De acordo com relatos da codirigente filha, a permanência na incubadora foi se tornando inviável: " começamos a prestar serviço e ganhar muito dinheiro, de repente veio uma norma da ANVISA que dizia 'vocês não podem mais fazer assim' e dentro da incubadora não tinha como fazer as adaptações necessárias, então caiu muito nosso faturamento...". Nas palavras do codirigente pai: "a Beta nunca conseguiu licença da ANVISA pra funcionamento ali... implementar as normas de controle de qualidade dos produtos lá na incubadora era impossível..."

Dadas as circunstâncias de dificuldades da empresa e ainda o desejo dos codirigentes de desenvolver a área comercial da Beta, empenharam-se na contratação da consultoria. A Biominas realizou as negociações e contratou a consultoria de uma organização internacional renomada e experiente no setor da indústria farmacêutica e biotecnológica.

Pode-se dizer que o conflito cognitivo nessa equipe é facilitado pela longa relação de trabalho entre os codirigentes. Além disso, trata-se de uma equipe de direção familiar, formada por pai e filha. Parece que esse fato influenciou mais o processo de contratação da consultoria como tentativa de se continuar o negócio de família, especialmente importante para a codirigente filha, a qual se dedica exclusivamente à Beta.

Evidenciou-se que houve muitas discussões entre os codirigentes a respeito dos rumos da empresa. O debate de ideias, outro fator de destaque que muito representou os conflitos cognitivos nesse processo 
de decisão estratégica, surgiu diante das diferentes alternativas analisadas: fechar a empresa, alugar uma sede, realizar parceria comercial ou produtiva. O codirigente pai demonstrou interesse em desativar o negócio e um excessivo apego em negociar seu trabalho de pesquisa em termos de valores financeiros.

Com a contratação da consultoria, os codirigentes da Beta foram para os Estados Unidos e lá tiveram a oportunidade de realizar várias reuniões de negociação, contudo nenhum negócio se concretizou, conforme relato do codirigente fundador: “...ai devido a problema regulatório e de patentes nós não conseguimos absolutamente nada..."

Desmotivados, os codirigentes cogitaram a alternativa de desativar a empresa. Foi nesse momento que surgiu uma oportunidade, identificada como segundo processo de decisão estratégica: formar parceria com uma indústria do setor veterinário. Tal parceria permitiu a saída da empresa Beta da incubadora em uma fase crítica. Conforme relato do codirigente pai, aconteceu dessa forma: "foi em uns 6 meses de conversa, eles (empresa parceira) convidaram a gente pra ocupar um espaço aqui em um anexo, pra trabalhar e ser o braço de $P \& D$ deles..."

Houve discordâncias entre os codirigentes, manifestação de conflito cognitivo importante, marcada pela forma de a administradora racionalizar o trabalho e pela maneira de o pesquisador cientista valorizar suas criações na empresa. Os codirigentes discordavam abertamente sobre os benefícios e valores nas negociações com a empresa parceira. Nos relatos da codirigente filha isso se torna absolutamente claro: "muita interferência externa ele (pai) fica bravo. Se as coisas pudessem ser apenas do jeito que ele, pesquisador, quer e pensa que tem que ser, é tudo muito fácil...ele acha que eles têm que fazer um aporte e fazer a planta do jeito que a gente quer..."

Tal discordância sobre a forma de realizar a parceria originava-se de uma interpretação divergente, fruto da formação profissional dos dirigentes. A filha tinha visão de mercado sobre quanto se poderia pagar por uma inovação científica, enquanto o codirigente pai parecia supervalorizar suas pesquisas, resultado de uma vida na carreira de médico pesquisador na universidade. Pode-se afirmar que, gradativamente, a parceria iniciada por meio de um comodato de área obteve progressos relevantes, inclusive, vários outros testes de controle de qualidade de produtos foram encomendados.

A crescente demanda por serviços trouxe à tona o terceiro processo de decisão estratégica: o controle de qualidade. Esse controle surgiu para assegurar a gestão da viabilidade técnica de prestações dos serviços, melhorar os já existentes e sustentar a implantação de novos. Os codirigentes perceberam que esse tipo de gestão poderia ajudá-los a lidar com dificuldades de planejamento, típicas da realidade de PEs, especialmente as que atuam no setor de pesquisa e desenvolvimento (P\&D). Para tanto, contratou-se uma funcionária pós-doutora na área farmacêutica para exercer a função de diretora científica e auxiliar a gestão de qualidade técnica da prestação de serviços.

Em decorrência da natureza específica do setor de atuação da empresa, os codirigentes se interessaram pela gestão da qualidade não apenas focada nos procedimentos adotados no laboratório, mas também com práticas de controle gerencial e de documentação. Foram incluídas a gestão de aquisição de material, cotação e contratos de fornecedor e consumidor, controle eletrônico de documentação, sistemas e fluxos de informação dentro da empresa.

O quarto e último processo de decisão estratégica, o estabelecimento de sociedade com os parceiros atuais, relaciona-se com o estreitamento dos negócios entre a Beta e a empresa parceira. Com o tempo, mais serviços foram requisitados até chegar à proposta recente de sociedade com aquisição de $50 \%$ da Beta, tornando-a composta por seis sócios nas seguintes porcentagens: codirigente pai 35\%, codirigente filha mantendo os $15 \%$ e os demais $50 \%$ divididos entre quatro novos sócios.

\subsection{Gama}

Uma explosão de crescimento nos negócios da empresa trouxe como efeito colateral várias dificuldades na gestão de pessoas e acarretou a inserção de práticas de RH, primeiro processo de decisão estratégica identificado na Gama nos últimos cinco anos. No final da década de 2000, foram realizadas muitas contratações e em decorrência disso, os codirigentes passaram a enfrentar muitos problemas. Havia o agravante de gerenciar funcionários de plantão para realizações da assistência técnica, alta rotatividade e os desencontros na comunicação interna. No relato do codirigente dois percebe-se a 
dimensão desse crescimento: “.... empresa cresceu muito, quando a gente tinha 10, 15, 20 funcionários conseguia falar um por um. Apesar de não ser o ideal, a hora que você chega perto de 50, muitas vezes, você nem sabe o nome das pessoas direito, eu não sei o nome de todas as pessoas da empresa...".

A gestão do bem estar das pessoas no trabalho começou a preocupar um dos codirigentes, que alimentou muitos debates de ideias, um fator de destaque do conflito cognitivo que convenceu outro codirigente a apoiá-lo nas mudanças necessárias. Tais debates se iniciaram em torno da importância de se cuidar da gestão dos funcionários e tê-los trabalhando em uma sede com instalações adequadas, e em seguida baixar a rotatividade.

A abertura ao diálogo na equipe de direção, composta por dois amigos de longa data, fez a diferença nesse processo decisório. Tal fator de destaque do conflito cognitivo tornou-se evidente diante do esforço do codirigente um em estabelecer diálogos e demonstrar ao codirigente dois a importância de cuidar das pessoas. Foi possível constatar que os codirigentes resolveram as divergências de uma maneira que um conseguiu convencer o outro sem, contudo, impor seu ponto de vista.

O segundo processo de decisão estratégica identificado envolveu um período de grande crescimento da Gama. No ano de 2010 houve a implantação da nota fiscal eletrônica no país. A fim de manter a tendência de crescimento, os codirigentes realizaram a inclusão dessa nota para aperfeiçoamento do software CEASA, importante produto do seu portfólio.

Pode-se constatar que os codirigentes se empenharam na busca de novos clientes, a despeito das dificuldades técnicas vislumbradas na prestação de serviços, decorrentes das grandes mudanças fiscais no sistema. Mas, é possível dizer que isso ocorreu apenas devido a um relevante fator de destaque do conflito cognitivo, a forte complementaridade na equipe de direção.

O codirigente um, durante muitos anos, foi o responsável técnico pela programação desse sistema. Por esse motivo, sua grande influência foi constatada nesse processo de decisão estratégica. Os codirigentes relataram que, tecnicamente, essa foi uma época complicada e problemática para a empresa. Nesse processo a abertura ao diálogo foi fundamental ao despertar os codirigentes para ponderações que deveriam ser realizadas sobre as alterações nesse produto.

Com a inserção da nota fiscal eletrônica, registrou-se na empresa um significativo aumento de clientes do produto CEASA e também alguns problemas de organização do trabalho. Conforme relato da diretora de projetos da empresa: “... a gente foi vendendo e vendendo aí foi onde a gente deu outro boom de crescimento e aí, ás vezes, a gente se perdia um pouco na qualidade e veio a organização e os departamentos..." Surgiu então, o terceiro processo de decisão estratégica, a departamentalização de setores específicos para estruturar a prestação dos serviços de softwares.

O quarto processo de decisão estratégica envolveu a elaboração da nova identidade visual da Gama. Surgiu a partir da constatação dos codirigentes a respeito da necessidade de alinhar os dois produtos principais da empresa, hotel e CEASA, com a imagem da marca e assim, conseguir se apresentar melhor no mercado. O codirigente um explicou que o primeiro logotipo da empresa estava voltado somente para hotelaria, pois nele havia estrelas e nenhuma referência ao produto CEASA, o qual havia se destacado nos últimos tempos.

Esse processo de decisão gerou muitos debates de ideias, fator de destaque do conflito cognitivo que desencadeou a seguinte controvérsia entre os codirigentes: a materialização do foco dado aos dois produtos precisaria envolver a mudança na marca da empresa? Justificaria o alto custo envolvido nesse processo? Pode-se verificar que esses questionamentos partiram do codirigente dois, o qual, nas palavras do codirigente um é: "mais matemático e racional". Nesse processo de decisão estratégica, tornou-se evidente a diferença de personalidade dos codirigentes.

O quinto e último processo de decisão estratégica diz respeito à iniciativa de contratação de consultoria especializada para guiar o futuro promissor da Gama. Pode-se perceber que o seu rápido crescimento motivou os codirigente a buscar ajuda externa para estruturá-la.

Ficaram evidentes nesse caso as limitações enfrentadas no planejamento futuro, e esse processo de decisão estratégica veio justamente para dar suporte à transição de PE para uma média organização. Acostumados a programar sistemas, atividade desenvolvida no início, os codirigentes relataram um "forte lado técnico" e por isso, dificuldades de também se aprofundarem na gestão propriamente dita. 


\subsection{Delta}

O primeiro processo de decisão estratégica identificado, a criação do produto Delta, foi realizado pelos três codirigentes, até então colegas de trabalho, que se demonstravam insatisfeitos com a filosofia de gestão da empresa em que trabalhavam. Após isso, fundaram o próprio negócio, amparados por propósitos bem específicos.

Pode-se constatar que foi a partir do choque de propósitos na condução das relações com clientes que, inicialmente, os codirigentes um e dois, grandes amigos, passaram a se reunir, ainda informalmente. Nas reuniões informais discutiam sobre as dificuldades de se manterem no emprego e acabaram ganhando como aliado o codirigente três.

Os debates para chegarem à ideia de um produto original foi um rico exercício, no qual a equipe de direção pôde começar a testar seu funcionamento antes da empresa formalizada. Além disso, consolidou a confiança, fator de destaque do conflito cognitivo essencial nesse processo. A partir da criação do produto Delta, os codirigentes formalizaram a empresa. Contudo, os resultados práticos dessa decisão foram frustrados e levaram os codirigentes à realização do segundo processo de decisão estratégica, a transição de produto para consultorias, e se tornarem uma empresa prestadora de serviços.

Esse processo de decisão estratégica ocorreu até o momento em que os codirigentes constataram, na primeira prestação de serviços, que por meio da consultoria poderiam conquistar o diferencial perseguido enquanto empresa. Nesse momento, intensificaram-se os debates de ideia, fator de destaque do conflito cognitivo que os despertou para a possibilidade de manter a empresa apoiada em transparência, livre de qualquer politicagem e oferecer consultorias, "embora não fossem tecnicamente os melhores..." (relato do codirigente um).

Em seguida, surgiu o terceiro processo de decisão estratégica: exploração de diferencial no design de software. Tal processo envolveu, além da melhoria na apresentação do sistema, a contratação de um profissional específico para trabalhar o design dos projetos. Com a montagem do escritório da empresa, intensificaram-se os projetos de consultoria e a prestação de serviços seguia funcionando muito bem, por meio do trabalho dos desenvolvedores e programadores; entretanto, os codirigentes ainda se mostravam insatisfeitos com o aspecto visual do sistema, o qual impactava negativamente, inclusive no valor cobrado pelo software.

O quarto e último processo de decisão estratégica foi concernente à entrada e posterior saída de um sócio na equipe de direção da Delta, relacionado com o ato de agregar mais um membro na equipe de direção com o objetivo de elevar o nível conceitual e acadêmico dos projetos desenvolvidos.

A princípio, o novo membro trouxe importantes discussões, entretanto não conseguiu trabalhar em sintonia na equipe. Essa nova composição societária, com o claro objetivo de agregar conteúdo conceitual, foi frustrada. Ao longo de dois anos, muitos atritos gerados no trabalho foram redirecionados para o âmbito pessoal; assim, a situação ficou insustentável a ponto de culminar na saída do novo codirigente.

Pode-se evidenciar que houve discordâncias, importante fator de destaque do conflito cognitivo que não pode ser mantido apenas como divergência de pontos de vista entre o novo membro e os codirigentes fundadores. As fortes discordâncias levaram ao processo de decisão estratégica de retomar a equipe com os três membros originais. Em síntese, essa retomada se deu devido às dificuldades dos codirigentes de manter o conflito apenas na dimensão cognitiva.

\section{Elementos essenciais do conflito cognitivo nos processos de decisão estratégica das PE}

Considerando-se os quatro casos estudados, tornou-se muito evidente que o conflito pode ser benéfico e prejudicial para a eficiência da equipe em processos de decisão estratégica, dependendo do seu tipo, respectivamente cognitivo ou afetivo, como sugerem Amazon et al. (1995) e Diánez-González e Camelo-Ordaz (2016). Olson et al. (2007) alertam para o fato de que, embora o conflito cognitivo possa gerar o conflito afetivo, sujeito a ser prejudicial, ele é extremante importante em processos de decisão estratégica mais complexos, conduzidos em ambiente constantemente mutáveis.

Para os casos de PEs estudados, essa perspectiva apontada pelos autores se provou. Pode-se 
constatar que, em especial a Beta, empresa do setor farmacêutico, se beneficiou dos conflitos cognitivos em seus processos de decisão altamente complexos, inclusive em ambiente mais hostil do ponto de vista da atuação governamental. Essa pesquisa relaciona-se muito ao estudo mais recente conduzido por De Dreu (2008), no qual o autor defende que as funções positivas do conflito podem de fato ser encontradas e enfatiza que as consequências positivas do conflito cognitivo surgem apenas em circunstâncias muito específicas. Parece que as PEs pesquisadas neste estudo se enquadram nesse conjunto especial, sendo elas a exceção à regra.

A partir dos resultados desta pesquisa, pode-se reafirmar que nem todos os tipos de conflito têm um efeito positivo sobre processos de decisão estratégica, conforme defenderam os estudos de Jehn et al. (2008), Mello e Delise (2015) e Tsai e Bendersky (2015). Um resultado importante encontrado na pesquisa diz respeito ao que De Wit et al. (2012) esclarecem. Segundo os autores, conflitos cognitivos são facilmente mal interpretados como conflitos afetivos porque os pontos de vista relacionados com os processos de decisão estratégica, muitas vezes, se tornam fortemente interligados com a visão do codirigente.

Com base na análise dos dados, observou-se que, semelhantemente, as PEs estudadas conciliaram razão e emoção em vários processos, dentre eles: abertura de sociedade na Beta para garantir um legado na empresa familiar; inclusão do filho na equipe de direção da Alpha, de modo a permitir um espaço para sua atuação na empresa; transição para a prestação de serviços em consultoria na Delta, no qual manter juntos os membros da equipe era a prioridade.

Por estarem conscientes de seus conflitos afetivos e com o fito de evitá-los, assim como estimular apenas os de modalidade cognitiva, as quatro PEs estudadas desenvolveram mecanismos tais quais: comunicação aberta, boa integração e, ao mesmo tempo, foco no cerne das questões a respeito do processo decisório, não se perdendo em questões pessoais (LOUGHRY; AMASON, 2014; TJOSVOLD; WONG; FENG CHEN, 2014; TSAI E BENDERSKY, 2015).

Para entender melhor a natureza do conflito cognitivo e do afetivo é preciso identificar os seus antecedentes. Mooney et al. (2007) examinaram os antecedentes relativos à abertura para dialogar e às discordâncias, cuja relação com conflitos tem sido geralmente consistente e concluíram que tais aspectos promovem o conflito cognitivo. Os resultados desse estudo estão alinhados com os achados da presente pesquisa.

Contudo, tais achados contrariam as considerações do trabalho de De Dreu (2008), no qual se defende que ao estimular o debate aberto e a troca de ideias conflitantes, pode-se estimular inadvertidamente o conflito afetivo também. Nas equipes de direção estudadas, essa tendência não ocorreu, talvez porque os codirigentes tenham buscado condições para atenuá-la.

Pode-se constatar que a confiança, favorecedora do conflito cognitivo, surgiu como fator marcante e atenuante nas relações das equipes. Tal constatação originou-se da transparência e da reciprocidade muito presente nas interações entre os codirigentes das PEs, conforme relatos de suas entrevistas. Assim como nos estudos de Clerkin e Jones (2013) e O’neill, Allen e Hastings (2013), nesta pesquisa tornou-se possível incluir questões de confiança como um dos fatores que sustentaram o conflito cognitivo.

Os resultados da pesquisa demostraram que a confiança baseada em competência no campo de atividade fortaleceu a interação dos codirigentes nos diferentes processos de decisão estratégica. Dessa forma, os estudos de Olson et al. (2007) estão relacionados com o resultado da pesquisa, uma vez que indicam uma forte relação positiva entre o conflito cognitivo e confiança advinda de competência.

Importante se faz saber que as relações de confiança conferiram às equipes maior abertura para desafiarem as perspectivas como sugerem Olson et al. (2007) e O'neill, Allen e Hastings (2013). Nas PEs estudadas, constatou-se essa abertura, a qual conduziu os codirigentes a questionarem uns aos outros, sem medo de serem ridicularizados ou de receberem qualquer retribuição. Com essa mesma expectativa, Woods (2012) afirma: o conflito é um combustível que promove novas soluções estratégicas.

A grande abertura ao diálogo, constatada nas PEs estudadas, é um resultado que se alinha às perspectivas dos autores citados acima. Note-se que nas PEs estudadas, processos de decisão estratégica viscerais foram conduzidos em momentos de crise ou em circunstâncias complexas. Diante deles, os codirigentes tiveram pouco tempo para calcular as probabilidades numéricas e analisar cada desfecho 
possível. Nessas situações sem precedentes e, portanto, carentes de informações concretas, tornou-se evidente que os processos de decisão estratégica foram conduzidos com mais amparo dos conflitos cognitivos.

Neles, houve tempo apenas para pesar argumentos e avaliar ideias debatidas. As técnicas modernas como análise de cenários e projeções estavam ausentes; portanto, os conflitos cognitivos triunfaram sobre o controle e a racionalidade. Tal constatação corrobora o pensamento de Eisenhardt e Zbaracki (1992), os quais propuseram a criação de uma visão mais realista em torno dos processos que envolvem a tomada de decisão estratégica a partir de acurada análise da literatura acerca do tema.

Empiricamente, Alcantar e Ngwenyama (2015) também encontraram resultados semelhantes ao estudarem os gerentes de PEs que tomam decisões estratégicas, predominantemente com base em suas experiências. Este comportamento foi considerado intrigante no estudo porque desafia a prescrição teórica para se adotar decisões estratégicas bem-sucedidas. Os modelos existentes na literatura, os quais incluem procedimentos analíticos com avaliação quantitativa de dados e simulação, não foram encontrados na realidade empírica das sete PEs pesquisadas por esses autores.

De modo geral, os dados coletados no presente estudo indicam que os processos de decisão estratégica das quatro PEs são caracterizados por: uma abordagem mais informal para o planejamento, o aprender fazendo, a participação direta dos codirigentes, suas preferências e características pessoais. Nelas, a informalização resulta do conflito cognitivo, sem racionalização ou planejamento formal, não há rotinas rígidas ou procedimentos formais pré-concebidos para se decidir ou mesmo um controle minucioso dos resultados.

Observe-se que é como relata o fundador da Alpha: "Quando acontece o problema a gente senta e conversa e resolve ali". Todavia, há muita consulta ente os codirigentes, troca de informações e diálogo para debater ideias. Como diz a codirigente filha na Beta: "eu e meu pai aqui é muita conversa, eu mostrando pra ele como tem que ser e ele discutindo comigo os pontos de vista dele".

No modelo racional, os processos de decisão estratégica são frequentemente conduzidos por um único indivíduo, como esclarecem Brouthers et al. (1998). Nas PEs deste estudo, isso não ocorre, pois as equipes trabalham conjuntamente para melhor decidir e, inclusive os sócios minoritários em participação societária encontraram a possibilidade de participarem como os majoritários, devido à competência técnica revelada.

Assim como nos estudos de Brouthers et al. (1998) e Liberman-Yaconi et al. (2010), no presente trabalho também se chegou à conclusão de que os processos de decisão estratégica das PEs não podem ser compreendidos à luz de modelos racionais desenvolvidos para explicar tais processos nas grandes organizações.

Outro resultado relevante reside na evidência de que as características pessoais dos codirigentes, tais como as relacionadas com personalidade, campo de competência, experiência, percepções e valores tiveram muita influência nos processos de decisão estratégica identificados. Esse resultado está alinhado com a pesquisa realizada por Liberman-Yaconi et al. (2010), na qual afirmam que as características pessoais dos dirigentes influenciam, particularmente, os padrões de decisão estratégica.

Talvez seja difícil para os codirigentes discutir muitas ideias e equacionar distintas perspectivas necessárias para resolver problemas e tomar decisões estratégicas em equipe, no entanto, sem uma interpretação oposta ou diferentes visões, alternativas importantes podem ser desconsideradas. O uso cognitivo de oposições ou contradições nos processos de decisão estratégica estudados ajudou na busca criativa de soluções e confirmou o estudo de Woods (2012).

A principal contribuição deste estudo reside no seguinte fato: por meio da utilização de dados empíricos, pode-se afirmar que o processo de decisão estratégica das quatro PEs estudadas é apoiado na contraposição. Houve forte argumentação de ideias nesses processos e em meio ao diálogo emergiram novas direções estratégicas.

\section{Considerações Finais}

Este estudo buscou compreender como o conflito cognitivo pode contribuir para o processo de decisão estratégica em PEs administradas por codirigentes, membros de equipes de direção. Foram 
investigadas as etapas e os momentos cruciais desses processos a fim de se averiguar o comportamento dos codirigentes. Analisaram-se decisões estratégicas que, segundo relato dos mesmos, resultaram em uma descontinuidade clara nos rumos da empresa.

Pode-se afirmar que, nos últimos cinco anos, a capacidade dos codirigentes de manterem os conflitos no plano cognitivo proporcionou às PEs estudadas uma grande capacidade de resposta às oportunidades e ameaças a elas apresentadas. Tais respostas foram muito apoiadas no pensamento intuitivo que permeou os processos de decisão e conferiu-lhes alguma lógica.

Alguns padrões evidenciados nos processos de decisão estratégica permitiram fazer inferências a respeito de como eles ocorrem na realidade das quatro PEs de base tecnológica estudadas. Notou-se que nelas não há rotinas de desenvolvimento das decisões estratégicas, as quais, talvez, pudessem simplificar teoricamente o processo de decidir. Além disso, os resultados também revelaram que os processos de decisão estratégica estão carregados de preferências individuais dos codirigentes, relacionadas à formação profissional ou diretamente a interesses pessoais. Há fortes influências idiossincráticas, principalmente nas empresas familiares.

Importa destacar também que as PEs do setor de base tecnológica enfrentaram alterações mais frequentes, muitas delas inconsistentes com padrões do passado. Por isso, regulamentação governamental (caso Beta, controle de qualidade nos laboratórios), desenvolvimento e aplicação de novas tecnologias (caso Alpha, software na nuvem), novos concorrentes internacionais (caso Gama, setor de hotelaria) e espaços no mercado (caso Delta, prestação de serviços em consultoria), todos provocaram impactos significativos nas PEs estudadas.

Diante dessas alterações, se destacou a relação de confiança entre os codirigentes, sobretudo nas habilidades uns dos outros, o que fez gerar processos participativos de decisão estratégica, nos quais não foi constatada a dominação por parte de qualquer codirigente. Nas PEs Alpha e Beta, por exemplo, a influência técnica e aquela pautada em experiências passadas no setor de atuação se complementaram na maior parte dos processos de decisão estratégica identificados, evidenciando que neles predominou a avaliação conjunta dos codirigentes.

Importante se faz ainda alertar que, diante dos resultados desse estudo, não pode haver a sugestão de que possam ser utilizados genericamente para outras PEs. Note-se que, até mesmo dentre as quatro PEs estudadas, foi possível constatar que os processos de decisão estratégica conduzidos pelos codirigentes apresentaram características peculiares, pois as equipes de direção não se comportaram como um grupo homogêneo. Neste estudo houve variações, inclusive diante do fato de se ter empresas familiares, não familiares e mistas na composição das equipes.

A partir deste estudo, sugerem-se algumas dimensões de pesquisas futuras, a serem analisadas na realidade da PE. Aquelas particularmente de serviços, encontram-se sub-representadas na pesquisa em estratégia, no entanto, há uma necessidade de mais pesquisas nessa área, posto que o setor de serviços vem crescendo e se tornando economicamente representativo, conforme defendem Liberman-Yaconi, Hooper e Hutchings (2010).

Sugestão de potenciais estudos, que inclusive ajudariam na superação das limitações desse trabalho, envolvem métodos de coleta de dados diferentes dos adotados. Considerando que, no momento da entrevista, as recordações que levaram aos relatos sobre como as decisões foram tomadas nos últimos cinco anos, podem ter sido muito mais elaboradas e racionalizadas do que de fato foi o ocorrido na época da tomada de decisão, se sugere como estudo futuro, pesquisas longitudinais.

\section{REFERÊNCIAS}

ALCANTAR, J.; NGWENYAMA, O. Top management capabilities for SME's market entry decisions. Conference Proceedings, International Association for Management of Technology IAMOT, p.13481362, May, 2015.

Amason, A. C., Thompson, K. R., Hochwater, W. A., \& Harrison, A. W., (1995). Conflict: An dimension in successful management teams. Organizational Dynamics, 24(2), 20-35.

Amason, A. C.; Sapienza, H. (1997). The effects of top management team size and interaction norms on 
cognitive and affective conflict. Journal of Management, 23(1), 495-516.

Ates, A., Garengo, P., Cocca, P., \& Bititci, U. (2013). The development of SME managerial practice for effective performance management. Journal of Small Business and Enterprise Development, 20(1), 2854.

Behfar, K. J., Mannix, E. A., Peterson, R. S., \& Trochim, W. M. (2010). Conflict in small groups: The meaning and consequences of process conflict. Small Group Research, 42(2), 127-176.

Boeker, W., \& Wiltbank, R. (2005). New venture evolution and managerial capabilities. Organization Science, 16(1), 123-133.

BRADLEY, Bret $\mathrm{H}$. et al. Ready to rumble: How team personality composition and task conflict interact. Journal of Applied Psychology, v. 98, n. 2, p. 385, 2013.

BROUTHERS K.D.; ANDRIESSEN F.; NICOLAES I. Driving blind: Strategic decision making in small companies. Long Range Planning, v. 31, n.1, p. 130-138, 1998.

CARMELI, Abraham; TISHLER, Asher; EDMONDSON, Amy C. CEO relational leadership and strategic decision quality in top management teams: The role of team trust and learning from failure. Strategic Organization, v. 10, n. 1, p. 31-54, 2012.

Clerkin, T. A., \& Jones, K. J. (2013). A Study of Conflict in Top Management Decision Making: The Impact of Contribution Motive. Coastal Business Journal, 12(1), 34-51.

COLBERT, Amy E.; BARRICK, Murray R.; BRADLEY, Bret H. Personality and leadership composition in top management teams: Implications for organizational effectiveness. Personnel Psychology, v. 67, n. 2, p. 351-387, 2014.

De Dreu, C. K. W. (2008). The virtue and vice of workplace conflict: Food for (pessimistic) thought. Journal of Organizational Behavior, 29(1), 5-18.

De Wit, F. R. C., Greer, L. L., \& Jehn, K. A. (2012). The Paradox of Intragroup Conflict: A MetaAnalysis. Journal of Applied Psychology, 97 (1), 360-390.

DIÁNEZ-GONZÁLEZ, Juan Pablo; CAMELO-ORDAZ, Carmen. How management team composition affects academic spin-offs' entrepreneurial orientation: the mediating role of conflict. The Journal of Technology Transfer, v. 41, n. 3, p. 530-557, 2016.

EISENHARDT, K. M. Building Theories from Case Study Research. Academy of Management Review, v.14, n.4, p. 522-550, 1989.

Eisenhardt, K. M., \& Zbaracki, M. (1992). Strategic decision making. Strategic Management Journal, 13(1), 17-37.

Eisenhardt, K. M., Kahwajy, J. L., \& Bourgeois III, L. J. (1997). How management teams can have a good fight. Harvard Business Review, 75(4), 77-90.

Eisenhardt, K., \& Graebner, M. (2007). Theory Building from Cases: Opportunities and Challenges. Academy of Management Journal, 50(1), 25-32.

ESCRIBÁ-ESTEVE, A.; SANCHEZ-PEINADO, L.; SANCHEZ-PEINADO, E. The influence of Top management teams in the strategic orientation and performance of small and medium-sized enterprises.

British Journal of Management, v. 20, n. 3, p. 581-597, 2009.

FULLER-LOVE, N. Management development in small firms. International Journal of Management Reviews, v. 8, n. 3, p.175-190, 2006.

GLASER, B.; STRAUSS, A. The Discovery of Grounded Theory: Strategies for Qualitative Research. London: Wiedenfeld and Nicholson, 1967.

GODOI, C. K.; MATTOS, P. L. de. Entrevista qualitativa: instrumento de pesquisa e evento dialógico. In: Godoi, C. K.; Bandeira-de-Mello, R.; Silva, A. B. (Org.). Pesquisa Qualitativa em Estudos Organizacionais: paradigmas, estratégias e métodos. São Paulo: Editora Saraiva, 2006. 
GONZÁLEZ-ROMÁ, Vicente; HERNÁNDEZ, Ana. Climate uniformity: Its influence on team communication quality, task conflict, and team performance. Journal of Applied Psychology, v. 99, n. 6, p. 1042, 2014.

GREENE, Patricia G.; BRUSH, Candida G.; BROWN, Terrence E. Resources in small firms: an exploratory study. Journal of Small Business Strategy, v. 8, n. 2, p. 25-40, 2015.

HAMBRICK, D. Fragmentation and the other problems CEOs have with their top management teams. California Management Review, v.37, n.1, p. 110-127, 1995.

HAMBRICK, D.; Mason, P. Upper echelons: the organization as a reflection of its top managers. Academy of Management Review, v.9, n.2, p.193-206, 1984.

Hjerto, K. B., Hjerto, K. B., Kuvaas, B., \& Kuvaas, B. (2017). Burning hearts in conflict: New perspectives on the intragroup conflict and team effectiveness relationship. International Journal of Conflict Management, 28(1), 50-73.

IBRAHIM, A. Bakr. Strategy Types and Small Firms' Performance An Empirical Investigation. Journal of Small Business Strategy, v. 4, n. 1, p. 13-22, 2015.

Jehn, K. A., Greer, L., Levine, S., \& Szulanski, G. (2008). The effects of conflict types, dimensions, and emergent states on group outcomes. Group Decision and Negotiation, 17(6), 465-495.

KARANJA, Tabitha et al. Small business management. International Journal of Business and Social Science, v. 4, n. 16, 2013.

Katzenbach, J. R., \& Smith, D. K. (2005). The Discipline of Teams What makes the difference between a team that performs and one that doesn't? Harvard Business Review, July-August.

LIBERMAN-YACONI, L.; HOOPER, T.; HUTCHINGS, K. Toward a model of understanding strategic decision-making in micro-firms: exploring the Australian information technology sector. Journal of Small Business Management, v. 48, n.1, p. 70-95, 2010.

LIMA, E. A Gestão Estratégica de Pequenas e Médias Empresas Segundo a Abordagem da Aprendizagem Sistêmica. Gestão \& Planejamento, v.9, n. 1, p. 22-34, 2008.

LIMA, E. Estratégia de Pequenas e Médias Empresas: Uma Revisão. REGE -Revista de Gestão USP, v.17, n. 2, p. 169-187, 2010.

LIU, Feng; MAITLIS, Sally. Emotional dynamics and strategizing processes: a study of strategic conversations in top team meetings. Journal of Management Studies, v. 51, n. 2, p. 202-234, 2014.

LOHRKE, Franz T.; FRANKLIN, Geralyn M.; KOTHARI, Vinay B. Top Management Team Heterogeneity and SME Export Performance: Investigating the Role of Environmental Uncertainty. Journal of Small Business Strategy, v. 14, n. 1, p. 86-102, 2015.

LOUGHRY, Misty; C. AMASON, Allen. Why won't task conflict cooperate? Deciphering stubborn results. International Journal of Conflict Management, v. 25, n. 4, p. 333-358, 2014.

LUBATKIN, M. H.; SIMSEK, Z.; LING, Y.; VEIGA, J. F. Ambidexterity and performance in small-to medium-sized firms: The pivotal role of top management team behavioral integration. Journal of management, v. 32, n. 5, p. 646-672, 2006.

Marimuthu, M., \& Kolandaisamy, I. (2009). Can demographic diversity in top management team contribute for greater financial performance? An empirical discussion. The Journal of International Social Research, 2(1), 273- 286.

MAZZAROL, T.W.; REBOUD, S. The strategic management process. IN: The Strategy of Small Firms. Edward Elgar Publishing Ltd, Cheltenham UK, Northampton, MA, USA, 2009.

MCCARTHY, B.; LEAVY, B. Phases in the Strategy Formation Process: An Exploratory Study of Irish SMEs. IBAR, v. 21, n. 2, p. 55-80, 2000.

MELLO, Abby L.; DELISE, Lisa A. Cognitive Diversity to Team Outcomes The Roles of Cohesion and 
Conflict Management. Small Group Research, v. 46, n. 2, p. 204-226, 2015.

MILES, M.B.; HUBERMAN, A. M. Qualitative data analysis: an expanded sourcebook. California: Sage, 1994.

Mooney, A. C., Holahan, P. J., \& Amason, A. C. (2007). Don't take it personally: Exploring cognitive conflict as a mediator of affective conflict. Journal of Management Studies, 44(5), 733-758.

OLSON, B. J.; PARAYITAM, S.; BAO, Y. Strategic decision making: The effects of cognitive diversity, conflict, and trust on decision outcomes. Journal of Management, v. 33, n. 2, p. 196-222, 2007.

O'NEILL, Thomas A.; ALLEN, Natalie J.; HASTINGS, Stephanie E. Examining the "Pros" and "Cons" of Team Conflict: A Team-Level Meta-Analysis of Task, Relationship, and Process Conflict. Human Performance, v. 26, n. 3, p. 236-260, 2013.

PANDIT, N. R. The Creation of Theory: a Recent Application of the Grounded Theory Method. The Qualitative Report, v. 2, n. 4, p. 378-299, 1996.

Parayitam, S., Parayitam, S., Papenhausen, C., \& Papenhausen, C. (2016). Agreement-seeking behavior, trust, and cognitive diversity in strategic decision making teams: Process conflict as a moderator. Journal of Advances in Management Research, 13(3), 292-315.

PECH-VARGUEZ, J. L., CISNEROS, L., GENIN, E., \& CORDOVA, H. Cohérence et cohésion de l'équipe de direction dans la PME, Revue internationale P.M.E., v.23, n. 3, p. 188 -209, 2010.

SERVIÇO BRASILEIRO DE APOIO ÀS MICRO E PEQUENAS EMPRESAS ANUÁRIO DO TRABALHO NA MICRO E PEQUENA EMPRESA: 2010-2011. 4. Ed, São Paulo: SEBRAE; DIEESE, 2011.

STRAUSS, A.; CORBIN, J. Basics of qualitative research: techniques and procedures for developing Grounded Theory. 3 ed. Thousand Oaks: Sage, 2008.

TIHULA, S.; HUOVINEN, H. Reasons and Situational Factors behind the Formation of Management Teams and Other Teams in Small Firms. In: Fink, M.; Kraus, S. The Management of Small and Medium Enterprises. New York: Routledge, 2009.

TJOSVOLD, Dean; WONG, Alfred SH; FENG CHEN, Nancy Yi. Constructively managing conflicts in organizations. Annu. Rev. Organ. Psychol. Organ. Behav., v. 1, n. 1, p. 545-568, 2014.

TODOROVA, Gergana; BEAR, Julia B.; WEINGART, Laurie R. Can conflict be energizing? A study of task conflict, positive emotions, and job satisfaction. Journal of Applied Psychology, v. 99, n. 3, p. 451, 2014.

TSAI, Ming-Hong; BENDERSKY, Corinne. The Pursuit of Information Sharing: Expressing Task Conflicts as Debates vs. Disagreements Increases Perceived Receptivity to Dissenting Opinions in Groups. Organization Science, 2015.

VERREYNNE, Martie-Louise; MEYER, Denny; LIESCH, Peter. Beyond the Formal-Informal Dichotomy of Small Firm Strategy-Making in Stable and Dynamic Environments. Journal of Small Business Management, v. 1, 2014.

WEINGART, Laurie R. et al. The directness and oppositional intensity of conflict expression. Academy of Management Review, v. 40, n. 2, p. 235-262, 2015.

Woods, J. G. (2012). Using cognitive conflict to promote the use of dialectical learning for strategic decision-makers. Learning Organization, 19(2), 134-147.

Yazici, S., Yazici, S., Köseoglu, M. A., Köseoglu, M. A., Okumus, F., \& Okumus, F. (2016). Identification of growth factors for small firms: evidence from hotel companies on an island. Journal of Organizational Change Management, 29(6), 994-1029.

YIN, R.K. Estudo de caso: planejamento e métodos. 4. ed. Porto Alegre: Bookman, 2010. 